\title{
Disruptive Behavior Disorders and Psychopathic Traits in Adolescents: Empathy-Related Responses to Witnessing Animal Distress
}

\author{
Minet de Wied ${ }^{1}$ (D) Wim Meeus ${ }^{1} \cdot{\text { Anton van } \text { Boxtel }^{2}}^{2}$
}

Accepted: 12 April 2021 / Published online: 2 June 2021

(C) The Author(s) 2021

\begin{abstract}
Cruelty to animals is a symptom of conduct disorder and associated with psychopathic traits in childhood. One of the factors thought to contribute to animal cruelty is reduced empathy and concern for the well-being of animals. A first aim of this study was to examine empathy towards animals in distress in male adolescents with disruptive behavior disorders (DBD) and high or low psychopathic traits, and normal controls (NC). Psychopathic traits were assessed by the Antisocial Process Screening Device (APSD). Respondents were exposed to a short film clip depicting a baby bear in distress. Heart rate (HR) responses were monitored during film exposure. Afterwards, respondents were asked to report the emotions they had observed and experienced. Contrary to expectations based on research on human empathy, no group differences were found in empathy-related responses to witnessing animal distress. Both DBD groups and normal controls observed equal levels of distress in the baby bear, experienced as much empathy and sympathy, and showed similar levels of HR reduction during the most dramatic scene. Results suggest that empathy for humans does not generalize to animals, and vice versa. A second aim was to examine the associations between empathy-related responses and the broad concept of psychopathy as well as its dimensions. The relationships were different and for the most part reversed in the NC and DBD groups. Group proved to be an important moderating factor, indicating that results obtained within a sample of healthy adolescents do not generalize to adolescents with DBD, and vice versa.
\end{abstract}

Keywords Empathy · Disruptive behavior disorders $\cdot$ Adolescents $\cdot$ Callous-unemotional traits $\cdot$ Psychopathy

\section{Introduction}

Cruelty towards animals, included in the DSM-5 (American Psychiatric Association (APA) 2013) as a symptom of conduct disorder (CD), is associated with psychopathic traits in childhood (Dadds et al. 2006a; Gullone 2014; Hartman et al. 2019), co-occurs with various forms of offending in adolescence (Lucia and Killias 2011), and predicts interpersonal violence later in life (Longobardi and Badenes-Ribera 2019; Merz-Perez et al. 2001). One of the factors thought to contribute to animal cruelty is reduced empathy and concern for the

Minet de Wied

m.dewied@uu.nl

1 Department of Youth \& Family, Faculty of Social and Behavioral Sciences, Utrecht University, P.O. Box 80140, Heidelberglaan 1, Utrecht, TC 3508, The Netherlands

2 Department of Psychology, Tilburg University, P.O. Box 90153, 5000, LE Tilburg, The Netherlands well-being of animals (McPhedran 2009). Children and adolescents with conduct problems, especially those with psychopathic traits, are known to have little empathy for their fellow human beings (Pijper et al. 2017). However, less is known about their empathy towards animals. Studies with students suggest that inter-human and animal-directed empathy are related but also separable constructs with different sources of variation (McPhedran 2009). For this reason, it is important to further investigate empathy towards animals among youth who tend to mistreat animals in childhood. The current study examined different aspects of animal-directed empathy in male adolescents with disruptive behavior disorders (DBD), including conduct disorder (CD) and oppositional defiant disorder (ODD), and high versus low levels of psychopathic traits.

According to the DSM-5 (APA 2013), the essential features of $\mathrm{CD}$ is a repetitive and persistent pattern of behavior in which basic rights of others or major age-appropriate norms or rules are violated. ODD is a less severe type of disorder, characterized by a frequent and persistent pattern of angry/ irritable mood, argumentative/defiant behavior or 
vindictiveness. ODD may be a developmental precursor of $\mathrm{CD}$ in late childhood and adolescence, and both are associated with significant impairments in social, academic, or occupational functioning.

Callous-unemotional (CU) traits are often used to index psychopathic traits in children and adolescents with DBD (Frick et al. 2014). CU traits represent the affective dimension of child and adult psychopathy and include a lack of empathy, lack of guilt, and low emotional responsiveness (Frick and Hare 2001). Researchers in the field, however, argue that CU traits alone are not enough to identify children at risk to develop adult psychopathy (e.g., Colins et al. 2018; Lilienfeld 2018; Salekin 2017; Salekin et al. 2018). The construct of child and adult psychopathy is multifaceted, including interpersonal, affective and behavioral traits. Some researchers assume that a multifaceted model of psychopathy could be more beneficial in clinical practice and point to the importance of investigating the broader construct of psychopathy as well as its dimensions to get a more complete picture of the differences and similarities between child and adult psychopathy (Ribeiro da Silva et al. 2020). To address this call the current study examined empathy both at the dimensional and broad concept level of psychopathy as measured by the Antisocial Process Screening Device (APSD; Frick and Hare 2001). The APSD is a questionnaire measure of psychopathic traits in youth which has been modelled down from Hare's (1991/ 2003) Psychopathy Checklist-Revised (PCL-R) and includes the interpersonal (narcissism), affective (callousunemotional) and behavioral (impulsivity) dimensions.

Empathy is also multifaceted, including cognitive and affective components with trait and state-like properties (Cuff et al. 2016). Cognitive empathy includes the understanding of other people's emotions, empathic accuracy, perspective taking, and Theory of Mind (ToM). Affective empathy refers to the vicarious experience of another person's emotions. A distinction is often made between the matching of emotions (emotional contagion), feeling for another person (sympathy/ empathic concern) and feeling distress in response to another person's distress (personal distress) (Singer and Klimecki 2014). Questionnaire measures of empathy are normally used to asses trait-like aspects of both affective and cognitive empathy. State-like aspects of empathy are usually examined within laboratory settings. In the current study empathyrelated responses were assessed by verbal and physiological (heart rate) responses to an empathy-inducing film clip portraying an animal in distress.

Research suggests that the mechanisms underlying empathy problems associated with DBD may be different for DBD subtypes (de Wied et al. 2010). Lack of empathy observed in youth with psychopathic traits is thought to be associated with reduced amygdala responsiveness to distress cues (Blair 2013; Blair et al. 2014, 2018; Moul et al. 2012), reduced motivation and attention to emotional cues in others (Dadds et al. 2011; Viding and McCrory 2019), and/or shortfalls in the neurochemical systems involved in empathy (Moul et al. 2018). Empathy problems seen in the larger (undifferentiated) group of individuals with disruptive behavior disorders can have different sources, such as hostility or anxiety, possibly in conjunction with problems in emotion regulation (de Wied et al. 2010; Pijper et al. 2018).

To our knowledge, no studies have directly examined empathy towards animals in youth with DBD, nor in youth with psychopathic traits. Dadds et al. (2006a) examined the relationship between animal cruelty and CU traits in childhood using the Children and Animals Inventory (CAI) which includes a few items on animal empathy among many more items on animal cruelty. CU traits were inversely related to CAI total scores, which could mean that children with $\mathrm{CU}$ traits have little empathy for animals. Comparable results have been reported by Hartman et al. (2019) who examined the relationship between animal cruelty and CU traits using the CAI in children from families with domestic violence. Quite a few studies with healthy adolescents demonstrate inverse relationships between questionnaire measures of humandirected empathy and animal cruelty (Lucia and Killias 2011; Parkes and Signal 2017; Plant et al. 2019; Hawkins et al. 2017). Studies with students further demonstrate that individuals with low trait empathy are less empathically sensitive with regard to both human and animal targets (Prguda and Neumann 2014; Westbury and Neumann 2008), although the strength of the response depends largely on the characteristics of the target.

Perceived similarity and our instinctive need to protect offspring have been mentioned as possible sources of variation in empathy for human and non-human targets (Batson et al. 2005). According to the similarity hypothesis we feel more empathy towards humans than animals because humans are phylogenetically closer to us. According to the nurturance hypothesis we feel more empathy for childlike targets than adult targets (humans and animals alike) because they are more vulnerable and need protection. Studies with students have provided evidence for both hypotheses (Prguda and Neumann 2014; Westbury and Neumann 2008), though the role of similarity seems more modest than that of nurturance. Batson et al. (2005), for example, demonstrated that dissimilar childlike targets (children and puppies) evoke stronger empathy-related responses than corresponding adult targets.

\section{The Current Study}

The current study examined empathy-related responses to witnessing animal distress in adolescents with DBD and high or low levels of psychopathic traits and normal controls (NC). Respondents were exposed to a film clip about a little bear in distress. During film presentation heart rate (HR) responses 
were monitored. Afterwards respondents were asked to rate the bear's emotions (observed distress), whether they had experienced similar emotions (empathy) and whether they had felt compassion for the bear (sympathy). In empathy research, HR responses have been used to differentiate between sympathy and personal distress (Eisenberg et al. 1988a; Eisenberg et al. 1988b; Zhou et al. 2003). Sympathy is an other-oriented reaction, involving an outward focus of attention, which may consist of feelings of sorrow or concern for another person. Personal distress is a self-focused emotion, which may consist of feelings of discomfort or anxiety. Sympathy has been associated with cardiac deceleration during empathy-inducing film clips portraying sadness. Personal distress has been associated with cardiac acceleration during film clips portraying fear.

As yet, two studies have demonstrated reduced HR change from baseline during exposure to empathy-evoking film clips in children and adolescents with DBD and high CU traits (see Fanti et al. 2019 for a review). One study (AnastassiouHadjicharalambous and Warden 2008), showed that boys with $\mathrm{CD}$ and high $\mathrm{CU}$ traits exhibit less HR acceleration than those with low CU traits and normal controls when witnessing a boy in fear, while the other study (de Wied et al. 2012) showed that male adolescents with DBD and high CU traits exhibit less HR deceleration relative to those with low $\mathrm{CU}$ traits and controls when witnessing a peer feeling sad. In both studies, the high CU group reported less affective empathy than normal controls, but not less than the low CU group.

A first aim of this study was to examine whether empathy towards humans extends to animals. If youth with psychopathic traits are essentially insensitive to distress cues, we may expect them to show just as little empathy towards animals as they do towards humans in distress. Based on previous findings (de Wied et al. 2012), DBD adolescents with psychopathic traits were expected to show less HR change from baseline than those without psychopathic traits and normal controls. Furthermore, they were expected to observe less distress, and to experience less empathy/sympathy, especially with regard to normal controls. The APSD total index, as well as the three dimensions of psychopathy (narcissism, CU traits and impulsivity), were used to create subgroups of DBD adolescents with high versus low psychopathic traits. The current study explores whether different classifications produce different results.

A second aim was to examine the relationships between empathy-related responses and psychopathic traits at the broad construct level and the dimensional levels. Low empathy is a core feature of narcissism (Urbonaviciute and Hepper 2020), and negative relationships between trait measures of affective empathy and the three dimensions of psychopathy (narcissism, CU traits and impulsivity) have been demonstrated in a sample of detained adolescents (Gillen et al. 2018). Accordingly, negative relationships were expected between psychopathic traits, CU traits in particular, and all verbal indexes of empathy (observed distress, empathy, and sympathy). No specific relationships were predicted for psychopathic traits and HR change from baseline because children and adolescents with psychopathic traits may show subnormal autonomic responses while witnessing others in distress (e.g., Blair 2013). Furthermore, because the relationships between psychopathic traits and external correlates sometimes differ across samples (Poore et al. 2020), we also examined whether group (NC vs DBD) moderates the proposed relationships obtained for the various APSD dimensions.

\section{Method}

\section{Participants}

This study is part of a larger study of empathy for humans and animals in adolescents with DBD. The data relating to human empathy have been published elsewhere (de Wied et al. 2012). More detailed information about measures, apparatus and procedures can be found in this publication. The Medical Ethical Committee of the University Medical Center Utrecht approved the study protocol, and both parents and adolescents gave written consent prior to participation. Male adolescents with DBD were recruited from special schools for youth with severe behavioral problems $(n=31)$. Information letters were sent to parents of 89 adolescents. Following written parental consent, a sample of 51 adolescents was screened on the basis of diagnostic information contained in their files at school and information from teachers. The initial screening yielded a sample of 48 adolescents. They were all personally approached for participation in a study on empathic sensitivity. In total, 44 adolescents, aged between 12 and 15 years, agreed to participate in the study and signed an informed consent form. The presence of ODD or CD as set out in the DSMIV-TR (APA 2000) was assessed using the parent version of the Diagnostic Interview Schedule for Children (DISC-IV, Dutch version) (Ferdinand and van der Ende 2002). The one year time frame was used, and ODD was not diagnosed when CD was present. IQ was assessed using the Vocabulary and Block Design subtests of the Wechsler Intelligence Scale for Children-Revised for the Netherlands (WISC-RN) (see Wechsler 1974). Exclusion criteria for the DBD group included IQ $<80(n=3)$ and absence of current CD/ODD according to the DISC $(n=10)$. Of the 31 participants who met the criteria of ODD $(n=17)$ or CD $(n=14), 21$ had comorbid attention deficit hyperactivity disorder (ADHD) and 14 were on psychopharmacological treatment, specifically on methylphenidate $(n=12)$ or risperidone $(n=2)$.

Age-matched normal control (NC) male adolescents were recruited from a regular school $(n=32)$. Of the 63 parents and children who received an information letter, 38 agreed to participate in the study and completed an informed consent form. 
Exclusion criteria for the NC group included IQ $<80(n=2)$ or the presence of CD/ODD according to the DISC $(n=3)$. The data of one participant was lost due to procedural errors. Of the 32 normal controls three had ADHD, two respondents used methylphenidate.

\section{Measures}

Conduct Problems Parents and teachers completed the Child Behavior Checklist (CBCL/4-18; Achenbach 1991a) and Teacher's Report Form (TRF/4-18; Achenbach 1991b), respectively. The CBCL and TRF externalizing (aggressive, rule-breaking) and internalizing (withdrawn, somatic complaints, anxious/depressed) scales were used to confirm the presence of group differences in conduct problems.

Psychopathic Traits Psychopathic traits were assessed with the APSD (Frick and Hare 2001), in the Dutch translation (de Wied et al. 2014). The APSD is a 20 -item questionnaire designed to measure psychopathic traits in children and adolescents. The scale includes three subscales: narcissism (NAR; seven items), callous-unemotional (CU; six items), and impulsivity (IMP; five items). Two items that do not load on any of the scales were included in the APSD total index score. Parents and teachers completed the APSD. Answers were scored on a 3-point ordinal scale (0-2). The intercorrelations between parents and teachers for the APSD total index and the three dimensions ranged between .46-.56 (see Table 1). Parent and teacher scores were combined by using the highest score for each item, accordingly (see Frick and Hare 2001). The alpha coefficients for parent, teacher, and combined scores are presented in Table 1 . Internal consistency of the combined scores ranged from acceptable for $\mathrm{CU}(\alpha=.71)$ to good for the APSD total index $(\alpha=.93)$.

The APSD total index was used to assign participants into subgroups of DBD adolescents with high or low levels of psychopathic traits. DBD adolescents with a raw score $\geq 30$ on the APSD total index were assigned to the DBD/APSD+ group $(n=15)$. A raw score $\geq 30$ converts to a $T$-score $\geq 70$,

Table 1 Interrater reliability (parent $x$ teacher) and internal consistency of the APSD scales

\begin{tabular}{lllll}
\hline & \multirow{2}{*}{\begin{tabular}{l} 
Interrater reliability $(r)$ \\
\cline { 3 - 5 }
\end{tabular}} & \multicolumn{3}{l}{ Internal consistency $(\alpha)$} \\
\cline { 3 - 5 } & Parent $x$ Teacher & Parent & Teacher & Combined \\
\hline APSD & $.56^{* *}$ & .90 & .92 & .93 \\
NAR & $.52^{* *}$ & .86 & .90 & .89 \\
CU & $.46^{* *}$ & .63 & .76 & .71 \\
IMP & $.51^{* *}$ & .75 & .82 & .82 \\
\hline
\end{tabular}

Note. APSD = APSD total index $; \mathrm{NAR}=$ narcissism; $\mathrm{CU}=$ callous-unemotional; IMP = impulsivity

$* * p<.01$ which is considered markedly atypical. Those with lower scores were assigned to the DBD/APSD- group $(n=16)$. The DBD/APSD+ group included practically equal numbers of ODD $(n=7)$ and CD $(n=8)$, the DBD/APSD- group included more $\operatorname{ODD}(n=10)$ than $\mathrm{CD}(n=6)$. Within the $\mathrm{DBD} /$ APSD+ group, $60 \%$ had comorbid ADHD (47\% using methylphenidate). Within the DBD/APSD- group, $75 \%$ had comorbid ADHD ( $31 \%$ using methylphenidate).

The NAR, CU and IMP scores were also used to designate DBD subgroups. DBD adolescents with a raw score $\geq 10$ on the NAR dimension ( $T$-score $\geq 66$ ) were assigned to the $\mathrm{DBD} /$ NAR+ group $(n=18)$, and those with lower scores to the DBD/NAR- group $(n=13)$. A $T$-score in the range $66-70$ is considered moderately atypical. DBD adolescents with a raw score $\geq 9$ on the $\mathrm{CU}$ dimension $(T$-score $\geq 67)$ were assigned to the $\mathrm{DBD} / \mathrm{CU}+$ group $(n=14)$. Those with lower scores were assigned to the DBD/CU- group $(n=17)$. DBD adolescents with a raw score $\geq 9$ on the IMP dimension ( $T$-score $\geq$ 67 ) were assigned to the DBD/IMP+ group $(n=16)$, and those with lower scores to the DBD/IMP- group $(n=15)$.

\section{Animal State Empathy}

Materials Respondents were exposed to a film clip about a little bear in distress. The clip was assembled from a feature film (The Bear, 1988). A voice-over sketching the situation introduced the clip, in which a little bear is shown with his mother searching for food in a rocky area. When mother bear is hit by a rock rolling down and dies, the little bear is left alone. The bear clip has been used in previous studies with clinical samples of children with DBD (de Wied et al. 2005; Pijper et al. 2018). In both studies, the bear clip evoked stronger empathy-related responses than film clips portraying human peers in distress, possibly because of the bear's cuteness, vulnerability and innocence. Cute little animals are likely to evoke strong positive feelings (Endenburg 1995), which may facilitate empathy. Nurturant tendencies are proposed to be stronger towards baby animals than towards peers, especially when in need of protection (Batson et al. 2005), which may enhance empathic responses. Also, the notion that the bear is not responsible for his own suffering minimizes confounding influences of negative attributions (Hoffman 2000). The total running time of the clip was 160 -s (voice-over excluded). The first 10-s of the opening scene served as baseline. The camera follows the little bear and his mother who are searching for food (90-s) when suddenly the stones roll down (20-s). This short scene is accompanied by the sound of rolling stones and groans of the mother bear which can have a startling effect. The most pathetic moment is the final scene, when the little bear lies down next to his dead mother after he tried to save her. This scene was taken as the target period (40-s). Heart rate responses were analyzed during this empathy-evoking scene. 
To be complete, we also analyzed HR responses during the two preceding scenes (food and stones).

Self-Reports After the clip, the participants were asked to identify the quality and to rate the intensity of emotions portrayed by the little bear as well as the quality and intensity of their own emotions during the final scene. Responses indicating that the participant observed sadness or fear and experienced that same emotion were considered empathic responses. Next, the participant was asked whether he felt sorry for the bear and how strong this feeling was, which was considered a measure of sympathy. Empathic and sympathetic responses were rated on a 5 -point scale $(0=$ no empathy/sympathy, $4=$ maximal response).

Heart Rate Response The electrocardiogram (ECG) was recorded with electrodes on the chest (sternum-V6 lead), digitized at a rate of $1024 \mathrm{~Hz}$, and bandpass filtered $(5-30 \mathrm{~Hz})$ to suppress baseline shifts, exceptionally large T-waves, and high-frequency artifacts such as EMG potentials. Data were then visually inspected for remaining artifacts. An automatic procedure was executed to detect ECG R-waves and to make corrections for (a) prolonged heart periods due to missing Rwaves and (b) short heart periods due to false R-waves (for details of this procedure, see de Wied et al. 2009). The HR response was expressed as the difference score between mean HR during the target and baseline period (HR target HR baseline). The HR responses during the food and stones scene were similarly corrected for differences in HR-baseline. Raw HR during the baseline period was not significantly different between groups in all classifications ( $p$ 's > 1). Following the work of Eisenberg and colleagues (Eisenberg et al. 1988a; Zhou et al. 2003), HR deceleration during the target relative to baseline was used as an index of empathy/ sympathy. HR acceleration was used as an index of personal distress.

\section{Procedure}

Participants were individually tested in a laboratory room at the university. The room contained a testing area and observation unit partitioned by a one-way screen. Both units were equipped with a personal computer, one for stimulus presentation (in the test room) and one for online control of data collection (in the observation unit). Both computers were connected to a small portable digital recorder for the preprocessing and storage of physiological data (Vitaport II, TEMEC Instruments B.V., Kerkrade, The Netherlands). A program written in Delphi 6 was used to control stimulus presentation and to collect children's self-reports. The program also generated signals marking onset and offset of each film clip which were stored on the Vitaport II recorder. Respondents were told that they would view short film clips about which several questions would be asked. They were also told that physiological recordings would be made to examine bodily reactions during film exposure. Prior to the test session, all participants completed the two WISC-RN subtests in the test room. During film exposure, the experimenter remained in the observation unit from where the participant could be observed.

\section{Statistical Analyses}

ANOVAs and follow-up $t$-tests were used to examine differences in the descriptive characteristics and all empathy-related responses between DBD subgroups and controls. Repeated measures ANOVAs were carried out to investigate the course of HR-responses from the opening scene (food) up to and including the final scene (target). To examine how empathy relates to the broader concept of psychopathy (APSD total index) as well as its dimensions (NAR, CU, IMP), multiple hierarchical regression analyses (MRA) were performed with empathy-related responses as the predictors and the APSDscores (total and sub-scores) as criterium variables. Group (NC vs DBD) was included as a possible dichotomous moderator in all MRAs. Separate analyses were conducted for each predictor, given the small sample size. Probabilities of all tests were two-tailed. A significance level of .05 was adopted in all tests.

\section{Results}

\section{Descriptive Characteristics}

Descriptive characteristics of the NC group and DBD subgroups, classified according to the APSD total index as well as its dimensions are presented in Table 2 and Supplementary Table 2S. One-way analyses of variance (ANOVAs) and additional $t$-tests revealed no age differences, nor differences in intelligence between NC and DBD subgroups. The analyses demonstrated expected differences between DBD subgroups and normal controls on the CBCL and TRF externalizing, aggressive and rule-breaking scales, with higher scores for DBD adolescents than normal controls. In agreement with studies showing that youth with psychopathic traits show particularly high rates of police contacts (Frick et al. 2014), DBD adolescents with high scores on the APSD total index and its three dimensions obtained the highest scores on the TRF rulebreaking scale (higher scores than both other groups). Those with high scores on both the APSD total index and the CU dimension obtained highest scores on the CBCL rule-breaking scale. DBD adolescents with high scores on the $\mathrm{CU}$ dimension achieved highest scores on the CBCL and TRF aggressive scales as well, indicating that those with high $\mathrm{CU}$ traits exhibit high levels of externalizing behavior both at home and at school. In contrast, DBD youth with high levels of NAR or 
Table 2 Descriptive characteristics of normal controls (NC) and boys with disruptive behavior disorders (DBD) with low (-) vs high (+) levels on the APSD total index

\begin{tabular}{|c|c|c|c|c|c|c|c|}
\hline & \multicolumn{2}{|l|}{$\begin{array}{l}\mathrm{NC} \\
(n=32)\end{array}$} & \multicolumn{2}{|c|}{$\begin{array}{l}\text { DBD/APSD- } \\
(n=16)\end{array}$} & \multicolumn{2}{|c|}{$\begin{array}{l}\text { DBD/APSD+ } \\
(n=15)\end{array}$} & \multirow[b]{2}{*}{$F(2,60)$} \\
\hline & $M$ & $(S D)$ & $M$ & $(S D)$ & $M$ & $(S D)$ & \\
\hline Age & 13.75 & $(0.76)$ & 13.25 & $(0.78)$ & 13.93 & $(1.10)$ & 2.78 \\
\hline IQ & 99.09 & $(9.11)$ & 96.38 & $(10.70)$ & 96.93 & $(9.10)$ & 0.53 \\
\hline APSD & $12.91^{\mathrm{a}}$ & $(5.20)$ & $23.75^{\mathrm{b}}$ & $(5.37)$ & $32.67^{\mathrm{c}}$ & $(2.55)$ & $93.18 * * *$ \\
\hline NAR & $2.72^{\mathrm{a}}$ & $(2.05)$ & $7.50^{\mathrm{b}}$ & $(2.39)$ & $11.33^{\mathrm{c}}$ & $(1.79)$ & $92.50 * * *$ \\
\hline $\mathrm{CU}$ & $5.75^{\mathrm{a}}$ & $(2.83)$ & $7.25^{\mathrm{b}}$ & $(1.57)$ & $9.20^{\mathrm{c}}$ & $(1.66)$ & $11.45^{* * *}$ \\
\hline IMP & $3.84^{\mathrm{a}}$ & (1.94) & $7.19^{\mathrm{b}}$ & $(2.17)$ & $9.07^{\mathrm{c}}$ & $(0.80)$ & $47.88 * * *$ \\
\hline \multicolumn{8}{|c|}{ Child Behavior Checklist } \\
\hline Externalizing & $47.59^{\mathrm{a}}$ & $(8.24)$ & $69.31^{\mathrm{b}}$ & $(5.28)$ & $73.67^{\mathrm{b}}$ & $(7.73)$ & $81.06 * * *$ \\
\hline Aggressive & $52.81^{\mathrm{a}}$ & $(4.34)$ & $70.38^{\mathrm{b}}$ & $(9.04)$ & $75.47^{\mathrm{b}}$ & $(10.11)$ & $60.32 * * *$ \\
\hline Rule-breaking & $52.19^{\mathrm{a}}$ & $(2.96)$ & $66.69^{\mathrm{b}}$ & $(4.85)$ & $70.87^{\mathrm{c}}$ & $(8.79)$ & $77.87 * * *$ \\
\hline Internalizing & $49.63^{\mathrm{a}}$ & $(9.53)$ & $60.50^{\mathrm{b}}$ & (7.69) & $63.40^{\mathrm{b}}$ & $(8.98)$ & $15.13 * * *$ \\
\hline Withdrawn & $54.81^{\mathrm{a}}$ & $(4.68)$ & $61.37^{\mathrm{b}}$ & $(6.41)$ & $66.53^{\mathrm{c}}$ & $(9.06)$ & $18.39 * * *$ \\
\hline Somatic Complaints & 55.06 & $(7.44)$ & 58.56 & $(8.32)$ & 60.93 & $(9.06)$ & 1.94 \\
\hline Anxious/Depressed & $52.56^{\mathrm{a}}$ & $(4.67)$ & $58.82^{\mathrm{b}}$ & $(9.33)$ & $59.57^{\mathrm{b}}$ & $(8.03)$ & $8.88 * *$ \\
\hline \multicolumn{8}{|c|}{ Teacher's Report Form } \\
\hline Externalizing & $48.06^{\mathrm{a}}$ & $(8.41)$ & $66.50^{\mathrm{b}}$ & $(9.39)$ & $72.00^{\mathrm{b}}$ & $(6.56)$ & $52.77 * * *$ \\
\hline Aggressive & $53.31^{\mathrm{a}}$ & $(5.29)$ & $67.50^{\mathrm{b}}$ & $(1.66)$ & $73.07^{\mathrm{b}}$ & $(9.38)$ & $34.27 * * *$ \\
\hline Rule-breaking & $52.16^{\mathrm{a}}$ & $(4.29)$ & $64.56^{\mathrm{b}}$ & $(9.54)$ & $70.67^{\mathrm{c}}$ & $(7.55)$ & $43.94 * * *$ \\
\hline Internalizing & $44.16^{\mathrm{a}}$ & $(6.24)$ & $60.56^{\mathrm{b}}$ & $(7.73)$ & $60.73^{\mathrm{b}}$ & $(6.27)$ & $48.38 * * *$ \\
\hline Withdrawn & $51.41^{\mathrm{a}}$ & $(2.60)$ & $58.13^{\mathrm{b}}$ & $(5.56)$ & $60.53^{\mathrm{b}}$ & $(4.45)$ & $32.29 * * *$ \\
\hline Somatic Complaints & $50.38^{\mathrm{a}}$ & $(2.12)$ & $56.50^{\mathrm{b}}$ & $(8.77)$ & $57.67^{\mathrm{b}}$ & $(8.62)$ & $9.20 * * *$ \\
\hline Anxious/Depressed & $51.03^{\mathrm{a}}$ & $(1.81)$ & $61.56^{\mathrm{b}}$ & (7.89) & $59.13^{\mathrm{b}}$ & (6.94) & $25.00 * * *$ \\
\hline
\end{tabular}

Note. $\mathrm{APSD}=\mathrm{APSD}$ total index $; \mathrm{NAR}=$ narcissism; $\mathrm{CU}=$ callous-unemotional; $\mathrm{IMP}=$ impulsivity. Means with different superscripts are significantly different as revealed by $t$-tests $(p<.05)$

$* * * p<.001 ; * * p<.01$

IMP achieved significantly higher scores on all TRF externalizing scales than those with low levels of NAR or IMP, but not on the CBCL externalizing scales. The analyses further revealed significant differences between all DBD subgroups and normal controls on the CBCL and TRF internalizing, withdrawn and anxious/depressed scales, with higher scores for DBD adolescents than controls.

\section{Preliminary Analyses}

Prior to conducting the main analyses of this study, the empathy measures were subjected to independent samples $t$-tests, to compare DBD individuals who were using methylphenidate with those who were not. No significant group differences emerged on any of the empathy measure (all $p$ 's $>.1$ ). The scores of treated and untreated DBD participants were accordingly collapsed in all statistical analyses.

All participants in the NC group (100\%), and most in the DBD group ( $>85 \%$ ) identified sadness as the most prominent emotion of the little bear. Three respondents in the DBD group observed fear instead of sadness. Because they did not experience fear themselves (no affect match), they got an empathy score of 0 . Thus, all empathy ratings reflect empathic sadness in the current study.

Zero-order correlations between all empathy measures for the NC and DBD groups separately are shown in Table 3.

Table 3 Zero-order correlations between empathy-related responses, including HR responses during the food and stones scenes in the NC group (upper right corner) and DBD group (lower left corner)

\begin{tabular}{llllllll}
\hline & 1 & 2 & 3 & 4 & 5 & 6 \\
\hline 1. Observed distress & - & $.40^{*}$ & $.44^{*}$ & .00 & .09 & -.03 \\
2. Empathy & $.37 *$ & - & $.46^{* *}$ & .00 & .02 & -.04 \\
3. Sympathy & -.03 & $.60 * *$ & - & -.31 & -.30 & -.30 \\
4. HR_food & .35 & .17 & -.18 & - & $.90 * *$ & $.94 * *$ \\
5. HR_stones & .32 & .05 & -.32 & $.71 * *$ & - & $.86 * *$ \\
6. HR_target & $.38^{*}$ & .15 & -.13 & $.92^{* *}$ & $.68^{* *}$ & - \\
\hline
\end{tabular}

$* * p<.01 ; * p<.05$ 
Observed distress and empathy were significantly positively related in both groups, $r_{\mathrm{NC}}=.40, p=.02 ; r_{\mathrm{DBD}}=.37, p=.04$, indicating that those who observed more distress in the bear experienced more empathy. Observed distress was also significantly positively related to sympathy in the NC group, $r=.44, p=.01$, but not in the DBD group, $r=-.03$, ns. As can be expected, sympathy and empathy were significantly positively related in both groups, $r_{\mathrm{NC}}=.46, p=.01$; $r_{\mathrm{DBD}}=.60, p=.001$. Noteworthy are the negative correlations between sympathy and HR responses during the most pathetic (target), $r_{\mathrm{NC}}=-.30, p=.09 ; r_{\mathrm{DBD}}=-.13, p>.1$ and shocking (stones), $r_{\mathrm{NC}}=-.30, p=.09 ; r_{\mathrm{DBD}}=-.32, p=.08$, moments in both groups. Although the correlations were not significant, the overall pattern is consistent, and in agreement with previous findings that HR deceleration relates to sympathy (Zhou et al. 2003).

\section{Group Differences in Animal Empathy}

Means and standard deviations of all empathy measures are displayed in Table 4. Different from expectations, the ANOVAs yielded no significant group differences between DBD subgroups and controls on any of the empathy measures (all $p$ 's > .05). Repeated measures ANOVAs were conducted on HR responses during the successive scenes (food, stones, target) with group (NC, DBD subgroups) as the betweensubjects factor. Because the sphericity assumption was violated, the Greenhouse-Geisser Epsilon was used. Classifications based on the APSD total index, NAR, CU and IMP yielded similar results. That is, a significant main effect of scenes was found: $F_{\text {APSD total index }}(1,40 ; 83,80)=6.99, p=.001$, $\eta_{p}{ }^{2}=.10, F_{\mathrm{NAR}}(1,39 ; 83,25)=6.83, p=.005, \eta_{p}{ }^{2}=.10, F_{\mathrm{CU}}$ $(1,40 ; 83,76)=7.01, p=.005, \eta_{p}{ }^{2}=.11, F_{\text {IMP }}(1,40 ; 84,10)=$ $7.10, p=.004, \eta_{p}{ }^{2}=.11$, but no effect of group, nor significant interactions (all $p$ 's >.1). Overall, the HR response showed a significant linear trend with increasingly stronger HR deceleration from the food scene to the target scene: $F_{\mathrm{APSD}}$ total index $(1,60)=36.85, p=<.001, \eta_{p}{ }^{2}=.38, F_{\mathrm{NAR}}(1,60)=34.78, p=$ $<.001, \eta_{p}{ }^{2}=.37, F_{\mathrm{CU}}(1,60)=37.19, p=<.001, \eta_{p}{ }^{2}=.38$, $F_{\text {IMP }}(1,60)=36.84, p=.000, \eta_{p}{ }^{2}=.38$.

\section{Associations between Empathy-Related Responses and Psychopathic Traits}

Zero-order correlations between predictors and criterium variables within the NC and DBD groups are presented in Table 5 . The standardized regression coefficients $(\beta)$ for each predictor, $R$ square change $\left(\Delta R^{2}\right)$ on each step of the MRA, and total $R$ square values are presented in Table 6 . The skewness and kurtosis statistics of all scores were close to zero, indicating normality, except for observed distress (skewness = -2.6 ; kurtosis $=6.65$ ). The assumptions of normality, linearity and homoscedasticity of residuals were checked. The overall models of all MRAs were significant, mainly due to the strong contribution of group to the APSD total index and dimensional scores $(p$ 's $<.01)$.

At the global construct level, MRAs showed that group significantly moderated the relationship between sympathy and the APSD total index score. As can be seen in Table 5, the relationships were opposite to each other in the $\mathrm{NC}$ and DBD groups. In agreement with expectations, sympathy was significantly negatively related to the APSD total index score in the NC group, indicating that those with higher APSD total index scores reported less sympathy for the bear. In contrast, the relationship was positive, though not significant, in the DBD group. Furthermore, as seen in Table 5, significant relationships were found between the APSD total index score and the HR response during the stones scene (preceding the target scene) in both groups, though in opposite directions: Normal controls with higher APSD scores showed stronger HR acceleration witnessing the stones roll down, while DBD individuals with higher APSD scores showed stronger HR deceleration.

At the dimensional level, the MRAs showed that group significantly moderated the relationship between sympathy and IMP, as well as the relationship between the HR response (target) and NAR. Again, all relationships were reversed in both the NC and DBD groups. In agreement with expectations, sympathy was insignificantly negative associated with IMP in the NC group, but significantly positive with IMP in the DBD group. Moreover, the HR response (target) was significantly positively related to NAR in the NC group, indicating that normal controls with higher levels of narcissism showed more HR acceleration during the target scene. The relationship was reversed, though not significant, in the DBD group, suggesting that DBD individuals with higher levels of narcissism tend to show more HR deceleration during the target scene. Different from expectations, none of the empathy indexes were significantly related to $\mathrm{CU}$.

\section{Discussion}

The current study examined empathy towards animal distress in male adolescents with DBD and high or low levels of psychopathic traits and normal controls. Empathy-related responses were examined within the context of a film clip portraying a baby bear in distress. A first goal was to examine whether male adolescents with DBD, especially those with high levels of psychopathic traits, show subnormal levels of empathy towards animals. Contrary to expectations, no significant group differences emerged in any of the empathy related responses. Both DBD groups and normal controls observed equal levels of distress in the baby bear, experienced as much empathy and sympathy and showed similar reductions in HR during the most dramatic final scene. Classifications based on the broad construct of psychopathy as well as its dimensions 
Table 4 Means (M) and standard deviation scores (SD) of empathy-related responses to witnessing animal distress across NC and DBD subgroups with low (-) vs high (+) levels of psychopathic traits

\begin{tabular}{|c|c|c|c|c|c|c|c|c|c|c|c|c|c|c|}
\hline & \multicolumn{2}{|c|}{$\begin{array}{l}N C \\
(n=32)\end{array}$} & \multicolumn{2}{|c|}{$\begin{array}{l}D B D / A P S D- \\
(n=16)\end{array}$} & \multicolumn{2}{|c|}{$\begin{array}{l}D B D / A P S D+ \\
(n=15)\end{array}$} & \multirow{2}{*}{\multicolumn{2}{|c|}{$F^{l}$}} & \multirow[b]{2}{*}{$\eta_{p}{ }^{2}$} & \multicolumn{2}{|c|}{$\begin{array}{l}D B D / N A R- \\
(n=13)\end{array}$} & \multicolumn{2}{|c|}{$\begin{array}{l}\text { DBD/NAR+ } \\
(n=18)\end{array}$} & \multirow[b]{2}{*}{$F^{l}$} \\
\hline & $M$ & $(S D)$ & $M$ & $(S D)$ & $M$ & $(S D)$ & & & & $M$ & $(S D)$ & $M$ & $(S D)$ & \\
\hline \multicolumn{15}{|l|}{ Self-reports } \\
\hline Observed distress & 3.72 & $(0.52)$ & 3.31 & (1.35) & 3.33 & $(1.23)$ & & 1.30 & .04 & 3.46 & (1.13) & 3.22 & $(1.40)$ & 1.53 \\
\hline Empathy & 1.78 & (1.39) & 1.06 & (1.57) & 1.60 & (1.77) & & 1.19 & .04 & 1.46 & (1.61) & 1.22 & (1.73) & 0.79 \\
\hline Sympathy & 3.19 & $(0.93)$ & 2.63 & (1.63) & 2.93 & (1.10) & & 1.23 & .04 & 2.77 & $(1.48)$ & 2.78 & (1.18) & 0.96 \\
\hline \multicolumn{15}{|l|}{ HR reactivity } \\
\hline Food & -0.94 & $(6.20)$ & 0.87 & $(5.88)$ & -1.76 & $(5.35)$ & & 0.83 & .03 & 1.20 & $(6.28)$ & -1.56 & $(5.10)$ & 0.85 \\
\hline Stones & -1.01 & $(5.60)$ & 0.47 & (9.63) & -3.31 & (6.46) & & 1.15 & .04 & 1.85 & (10.28) & -3.68 & $(5.88)$ & 2.46 \\
\hline \multirow[t]{3}{*}{ Target } & -2.02 & (7.43) & -1.62 & (6.36) & -4.43 & $(5.78)$ & & 0.81 & .03 & -0.72 & $(6.70)$ & -4.62 & (5.34) & 1.42 \\
\hline & & \multicolumn{2}{|c|}{$\begin{array}{l}D B D / C U- \\
(n=17)\end{array}$} & \multicolumn{2}{|c|}{$\begin{array}{l}D B D / C U+ \\
(n=14)\end{array}$} & & & \multicolumn{3}{|c|}{$D B D / I M P-(n=15)$} & \multicolumn{2}{|c|}{$\begin{array}{l}D B D / I M P+ \\
(n=16)\end{array}$} & & \\
\hline & $\eta_{p}^{2}$ & $M$ & $(S D)$ & $M$ & $(S D)$ & $F^{l}$ & $\eta_{p}{ }^{2}$ & & M & $(S D)$ & $M$ & $(S D)$ & $F^{l}$ & $\eta_{p}^{2}$ \\
\hline \multicolumn{15}{|l|}{ Self-reports } \\
\hline Observed distress & .05 & 3.35 & $(1.32)$ & 3.29 & $(1.27)$ & 1.31 & .04 & & 3.27 & $(1.39)$ & 3.37 & $(1.20)$ & 1.34 & .04 \\
\hline Empathy & .03 & 1.35 & $(1.73)$ & 1.29 & $(1.64)$ & 0.71 & .02 & & 1.13 & $(1.64)$ & 1.50 & $(1.71)$ & 0.93 & .03 \\
\hline Sympathy & .03 & 2.94 & (1.39) & 2.57 & $(1.40)$ & 1.35 & .04 & & 2.67 & $(1.50)$ & 2.88 & $(1.31)$ & 1.08 & .04 \\
\hline \multicolumn{15}{|l|}{ HR reactivity } \\
\hline Food & .03 & 0.66 & $(4.00)$ & -1.70 & $(7.21)$ & 0.67 & .02 & & -0.86 & $(5.80)$ & 0.03 & $(5.75)$ & 0.15 & .01 \\
\hline Stones & .08 & 0.48 & $(8.75)$ & -3.60 & $(7.67)$ & 1.32 & .04 & & -0.96 & $(10.31)$ & -1.73 & $(6.30)$ & 0.06 & .00 \\
\hline Target & .05 & -1.71 & $(5.20)$ & -4.54 & $(7.04)$ & 0.82 & .03 & & -3.53 & $(5.80)$ & -2.48 & $(6.63)$ & 0.24 & .01 \\
\hline
\end{tabular}

Note. $\mathrm{APSD}=\mathrm{APSD}$ total index $; \mathrm{NAR}=$ narcissism $; \mathrm{CU}=$ callous-unemotional; $\mathrm{IMP}=$ impulsivity. $\mathrm{ANOVAs}$ examined differences between $\mathrm{NC}$ and DBD subgroups

${ }^{1} d f=2,60$

yielded exactly the same results. In earlier work with the same sample (de Wied et al. 2012), DBD adolescents with high CU traits showed significantly less empathy towards human peers in distress. This could mean that empathy for humans does not generalize to animals, though we should be careful when drawing conclusions since the human and animal clips differed in many ways.

The lack of support for group differences in animaldirected empathy may have several reasons. First, stimulus characteristics may have evoked stronger empathy-related responses in all respondents, including those with psychopathic traits. We know from studies with undifferentiated groups of school-aged children with DBD (de Wied et al. 2005), and DBD children with and without comorbid anxiety disorder (Pijper et al. 2018) that stimulus characteristics play a role in DBD children's reduced responsiveness to another's distress. In both studies, all children reported more empathy and sympathy when watching a baby bear in distress than when watching human peers in distress. It is quite possible that the theme of the bear clip (loss of the mother), together with characteristics of the baby bear (cuteness and vulnerability) enhanced empathy in all groups such that group differences did not emerge in the current study.

Second, because the bear clip is a strong emotional stimulus, it may have attracted attention to the bear's fate, which is a precondition for eliciting empathy. We know from previous studies that reduced attention to the emotions of others can be the cause of reduced empathy in individuals with psychopathic traits, and that explicitly directing attention to the emotions of the target may reduce group differences in empathy (van Baardewijk et al. 2009; Dadds et al. 2006b; Dadds et al. 2008; Meffert et al. 2013). In healthy persons, attending to affective film clips is generally associated with cardiac deceleration (e.g., Gomez et al. 2005; Kreibig et al. 2007), which may reflect stimulus intake or an orienting/attention response (Bradley et al. 2001; Cook and Turpin 1997). In the current study, cardiac deceleration was seen in all groups during the target scene, so it is possible that the bear clip generated equal levels of empathy across groups because salient cues attracted reflexive/involuntary attention. Increased attention to the sad situation of the baby bear may have triggered empathy and sympathy in all respondents, including those with 
Table 5 Zero-order correlations between the APSD scales, empathy-related responses and HR responses during the food and stones scenes

\begin{tabular}{|c|c|c|c|c|c|c|c|c|}
\hline & \multicolumn{4}{|c|}{$\mathrm{NC}(n=32)$} & \multicolumn{4}{|c|}{$\operatorname{DBD}(n=31)$} \\
\hline & APSD & NAR & $\mathrm{CU}$ & IMP & APSD & NAR & $\mathrm{CU}$ & IMP \\
\hline \multicolumn{9}{|l|}{ Self-reports } \\
\hline Observed distress & -.05 & .10 & -.16 & -.01 & -.03 & -.10 & -.20 & .17 \\
\hline Empathy & -.22 & -.25 & -.02 & -.24 & .13 & .03 & .05 & .27 \\
\hline Sympathy & $-.38 *$ & -.16 & -.30 & -.31 & .27 & .21 & .06 & $.46^{* *}$ \\
\hline \multicolumn{9}{|l|}{ HR reactivity } \\
\hline Food & .25 & .35 & .04 & .16 & -.26 & -.21 & -.27 & -.11 \\
\hline Stones & $.35^{*}$ & $.39 *$ & .10 & .28 & $-.48 * *$ & -.32 & $-.44 *$ & $-.41 *$ \\
\hline Target & .25 & $.36^{*}$ & .04 & .15 & -.26 & -.27 & -.25 & -.05 \\
\hline
\end{tabular}

Note. $\mathrm{APSD}=\mathrm{APSD}$ total index $\mathrm{NAR}=$ narcissism; $\mathrm{CU}=$ callous-unemotional; $\mathrm{IMP}=$ impulsivity

$* * p<.01 ; * p<.05$

psychopathic traits. This raises the question whether HR patterns may be considered to reflect focused attention, empathy related responses, or both.

Attention is an essential first step in the empathy process. However, the relationship between the empathizer and the person with whom one empathizes, personal characteristics of both parties and other contextual elements further determine the strength of the response (Main et al. 2017). The current findings demonstrate that under certain (perhaps most favorable) conditions, male adolescents with psychopathic traits show normal levels of empathy towards animals in distress. Nevertheless, they may well react differently to the suffering of other, perhaps less loveable animals in normal life. Empathy is a dynamic, mutual process that develops over time (Main et al. 2017). As yet, the context and relational dynamics of empathy have been largely neglected in research on empathy dysfunction in DBD individuals. Focusing on the dynamics of empathy is important because it can tell us more about the empathic capacity of individuals and the readiness to show empathy under different circumstances.

In the scope of previous results with the same sample, revealing subnormal levels of empathy for human peers among DBD adolescents with high CU traits (de Wied et al. 2012), the current results suggest that stimulus characteristics play a role in empathy problems seen in these individuals. This finding is compatible with the hypothesis that psychopaths have the ability to empathize but not always the propensity to empathize with others, as put forward by Keysers and Gazzola (2014). Alternatively, the results could be taken to mean that empathy does not generalize from animals to humans and that inter-human and animal-directed empathy represent different psychological concepts (McPhedran 2009). More systematic research is needed to uncover the mechanisms involved, to determine whether empathy for humans extends to animals (and vice versa), and whether animal-directed empathy plays a role in animal cruelty. This knowledge is important for combating animal cruelty, and to improve training programs in which animals are used to enhance empathy towards humans (e.g., Grommon et al. 2020).

A second goal of the current study was to examine mutual relationships between empathy-related responses and different components of psychopathy. There are two important findings. First, within both the NC and DBD groups, none of the empathy indexes were significantly related to the $\mathrm{CU}$ dimension. Self-reported sympathy was significantly related to the APSD total index in the NC group and the impulsivity dimension in the DBD group. The HR response during the target was only significantly related to the narcissism dimension in the NC group. Because the empathy-related responses were differentially related to the dimensions of psychopathy, results suggest that the broader construct of psychopathy might add more to the diagnostic picture than the $\mathrm{CU}$ dimension alone. Second, the relationships were different and for the most part reversed in both groups. Because the samples were small, most correlations did not reach significance. Nevertheless, group was found to significantly moderate the relationships between self-reported sympathy and both the global construct of psychopathy and the impulsivity dimension. Also, group significantly moderated the relationship between the HR response and the narcissism dimension. The relationships between empathy-related responses and psychopathic traits were in agreement with expectations in the NC group: Higher levels of psychopathic traits were associated with lower levels of self-reported sympathy and stronger HR acceleration (or less HR deceleration) during the target scene. In the DBD group the relationships were reversed and counter-intuitive, with higher levels of psychopathy being associated with higher levels of self-reported sympathy and stronger HR deceleration. Except for the relationship between the APSD total index score and sympathy in the NC group, none of the relationships were significant, however, so we have to be careful interpreting the results. 
Table 6 Hierarchical moderator regression analyses predicting psychopathic tendencies from empathy-related responses $(N=63)$

\begin{tabular}{|c|c|c|c|c|c|c|c|c|}
\hline & APSD & & NAR & & $\mathbf{C U}$ & & IMP & \\
\hline Predictor & $\Delta R^{2}$ & $\beta$ & $\Delta R 2$ & $\beta$ & $\Delta R^{2}$ & $\beta$ & $\Delta R^{2}$ & $\beta$ \\
\hline Step 1 & $.65 * * *$ & & $.65^{* *}$ & & $.23 * * *$ & & $.57 * *$ & \\
\hline Observed distress & & -.01 & & -.03 & & -.14 & & .07 \\
\hline Group & & $.80 * * *$ & & $.80 * *$ & & $.43 * * *$ & & $.76^{* *}$ \\
\hline Step 2 & .00 & & .00 & & .01 & & .00 & \\
\hline Observed distress & & -.05 & & .10 & & -.13 & & -.02 \\
\hline Group & & $.80 * * *$ & & $.81 * *$ & & $.42 * *$ & & $.76^{* *}$ \\
\hline $\begin{array}{l}\text { Observed distress } \mathrm{x} \\
\text { Group }\end{array}$ & & .03 & & -.14 & & .19 & & .09 \\
\hline Total $R^{2}$ & $.65^{* * *}$ & & $.81 * * *$ & & $.48 * * *$ & & $.75^{* * *}$ & \\
\hline Step 1 & $.65 * * *$ & & $.81 * * *$ & & $.21 * *$ & & $.85^{* * *}$ & \\
\hline Empathy & & -.01 & & -.05 & & .01 & & .02 \\
\hline Group & & .80 *** & & $.80 * * *$ & & $.46^{* * *}$ & & $.75^{* * * *}$ \\
\hline Step 2 & .01 & & .01 & & .00 & & .03 & \\
\hline Empathy & & -.14 & & -.14 & & -.03 & & -.18 \\
\hline Group & & $.80 * * *$ & & $.80 * * *$ & & $.46 * * *$ & & $.75^{* * * *}$ \\
\hline $\begin{array}{l}\text { Empathy x } \\
\text { Group }\end{array}$ & & .16 & & .12 & & .05 & & $.26^{\dagger}$ \\
\hline Total $R^{2}$ & $.66 * * *$ & & $.81 * * *$ & & $.21 * *$ & & $.77 * * *$ & \\
\hline Step 1 & $.65 * * *$ & & $.81 * * *$ & & $.22 * *$ & & $.75 * * *$ & \\
\hline Sympathy & & .02 & & .05 & & -.11 & & .09 \\
\hline Group & & $.81 * * *$ & & $.81 * * *$ & & $.44 * * *$ & & $.76^{* * *}$ \\
\hline Step 2 & $.04 *$ & & .01 & & .04 & & $.06^{*}$ & \\
\hline Sympathy & & $-.26^{\dagger}$ & & -.10 & & $-.40^{\dagger}$ & & -.26 \\
\hline Group & & $.80 * * *$ & & $.80 * * *$ & & $.43 * * *$ & & $.75^{* * *}$ \\
\hline $\begin{array}{l}\text { Sympathy x } \\
\text { Group }\end{array}$ & & $.34 *$ & & .18 & & $.36^{\dagger}$ & & $.43^{*}$ \\
\hline Total $R^{2}$ & $.68 * * *$ & & $.81 * * *$ & & $.26 * * *$ & & $.79 * * *$ & \\
\hline Step 1 & $.65 * * *$ & & $.65 * * *$ & & $.21 * *$ & & $.56^{* * * *}$ & \\
\hline HR_target & & .00 & & .02 & & -.05 & & .04 \\
\hline Group & & $.80 * * *$ & & $.81 * * *$ & & $.45 * * *$ & & $.75^{* * * *}$ \\
\hline Step 2 & $.02^{\dagger}$ & & $.03 *$ & & .01 & & .00 & \\
\hline HR_target & & .12 & & .16 & & .04 & & .09 \\
\hline Group & & $.80 * * *$ & & $.80 * * *$ & & $.41 * *$ & & $.75^{* * * *}$ \\
\hline $\begin{array}{l}\text { HR_target } \mathrm{x} \\
\text { Group }\end{array}$ & & $-.19^{\dagger}$ & & $-.23^{*}$ & & -.14 & & -.08 \\
\hline Total $R^{2}$ & $.82 * * *$ & & $.68 * * *$ & & $.23 * *$ & & $.75^{* * * *}$ & \\
\hline
\end{tabular}

Note. $\mathrm{APSD}=\mathrm{APSD}$ total index $; \mathrm{NAR}=$ narcissism; $\mathrm{CU}=$ callous-unemotional; IMP = impulsivity

$* * * p<.001 ; * * p<.01 ; * p<.05 ;{ }^{\dagger} p=.05$

Interestingly, significant relationships between the broader construct of psychopathy and HR responses were established in both the NC and DBD groups during the scene preceding the target, that is, the scene in which the stones roll down and hit the mother. Again, the relationships were reversed in both groups. In the NC group those with higher levels of psychopathic traits showed stronger HR acceleration (indicating personal distress) while in the DBD group they showed stronger HR deceleration (indicating focused attention, sympathy, or both). We did not ask the respondents what they felt during this particular scene, but the scene may have had a startling effect with various consequences for attention processes (Bradley et al. 2001).The opposing patterns are noteworthy and, if replicated, require more in-depth research into the underlying mechanisms.

The current study has several limitations and strengths. First, because the sample size in the current study was relatively small, results need replication with a larger number of respondents to draw firm conclusions. Second, the current study included only male adolescents and thus requires 
replication with female adolescents. Third, as in previous studies on human-directed empathy (e.g., de Wied et al. 2012) baseline HR was measured during the first 10-s period of the film clip. This may detract from the reliability of this measure since (1) such a period may be rather short to reliably measure resting HR, and (2) the current baseline period occurs at the early onset of the clip whereas HR may need a longer period to stabilize at the real resting baseline level (Hastrup 1986). The ANOVAs were therefore also performed with baseline HR measured during the first 100-s, but this yielded the same result. Fourth, a null result cannot provide evidence of absence. However, we believe the current null results are meaningful because (a) previous work with the same sample has demonstrated significant differences in human-directed empathy between DBD individuals and controls with partly similar indexes of empathy within a similar research setting (de Wied et al. 2012), and (b) the bear clip can be considered a valid instrument to arouse empathy in the laboratory as research has shown that this clip evokes stronger empathyrelated responses in children with DBD than film clips portraying human peers in distress (de Wied et al. 2005; Pijper et al. 2018). Finally, it is important to note that the APSD often shows weak reliability, especially on the CU dimension (Ribeiro da Silva et al. 2020; Frick and Hare 2001). In the current study, however, the APSD showed sufficient agreement across teachers and parents and acceptable to good reliability on all dimensions.

Strengths of the study can be seen in the inclusion of a welldefined sample of adolescents with ODD/CD and psychopathic scores in the (sub-) clinical range. A further strength is the inclusion of multiple indexes of empathy that allowed for the mapping of empathy-related responses at different levels of information processing. Furthermore, our results confirm that attending to an empathy-inducing film clip portraying sadness is associated with HR deceleration (e.g., Kreibig et al. 2007), which strengthens the internal validity of the study.

In conclusion, the current study examined animal-directed empathy in DBD subgroups and normal controls, as well as the relationships between empathy-related responses and psychopathic traits. Different from expectations, no group differences emerged: Male adolescents with DBD and high levels of psychopathic traits showed as much empathy towards a baby bear in distress as those with lower levels of psychopathic traits and normal controls. Because previous research with the same sample did find group differences in human-directed empathy (de Wied et al. 2012), the current results suggest that empathy for humans does not generalize to animals. Furthermore, empathy-related responses were differently associated with psychopathic traits within and between the DBD and $\mathrm{NC}$ groups, indicating that results obtained within a sample of healthy adolescents do not simply generalize to adolescents with DBD, and vice versa.
Supplementary Information The online version contains supplementary material available at https://doi.org/10.1007/s10862-021-09891-2.

\section{Declarations}

Ethical Approval All procedures performed in studies involving human participants were in accordance with the ethical standards of the institutional and/or national research committee and with the 1964 Helsinki declaration and its later amendments or comparable ethical standards.

Informed Consent Informed consent was obtained from all individual participants included in the study.

Conflict of Interest Minet de Wied, Wim Meeus, and Anton van Boxtel declare that they have no conflict of interest.

Open Access This article is licensed under a Creative Commons Attribution 4.0 International License, which permits use, sharing, adaptation, distribution and reproduction in any medium or format, as long as you give appropriate credit to the original author(s) and the source, provide a link to the Creative Commons licence, and indicate if changes were made. The images or other third party material in this article are included in the article's Creative Commons licence, unless indicated otherwise in a credit line to the material. If material is not included in the article's Creative Commons licence and your intended use is not permitted by statutory regulation or exceeds the permitted use, you will need to obtain permission directly from the copyright holder. To view a copy of this licence, visit http://creativecommons.org/licenses/by/4.0/.

\section{References}

Achenbach, T. M. (1991a). Manual for the child behavior checklist and 1991 profile. Burlington: University of Vermont, Department of Psychiatry.

Achenbach, T. M. (1991b). Manual for the teacher's report form and 1991 profile. Burlington: University of Vermont, Department of Psychiatry.

American Psychiatric Association (2000). Diagnostic and Statistical Manual of Mental Disorders (DSM-IV-TR, 4th ed., text revision). Washington DC: American Psychiatric Press.

American Psychiatric Association. (2013). Diagnostic and Statistical Manual of Mental Disorders (DSM-5tm). Washington DC: American Psychiatric Publishing.

Anastassiou-Hadjicharalambous, X., \& Warden, D. (2008). Physiologically-indexed and self-perceived affective empathy in conduct-disordered children high and low on callous-unemotional traits. Child Psychiatry and Human Development, 39, 503-517. https://doi.org/10.1007/s10578-008-0104-y.

Batson, C. D., Lishner, D. A., Cook, J., \& Sawyer, S. (2005). Similarity and nurturance: Two possible sources of empathy for strangers. Basic and Applied Social Psychology, 27, 15-25. https://doi.org/ 10.1207/s15324834basp2701 2.

Blair, R. J. R. (2013). The neurobiology of psychopathic traits in youths. Nature Reviews Neuroscience, 14, 786-799. https://doi.org/10. $1038 /$ nrn3577.

Blair, R. J. R., Leibenluft, E., \& Pine, D. S. (2014). Conduct disorder and callous-unemotional traits in youth. The New England Journal of Medicine, 371, 2207-2216. https://doi.org/10.1056/ NEJMra1315612.

Blair, R. J. R., Veroude, K., \& Buitelaar, J. K. (2018). Neurocognitive system dysfunction and symptom sets: A review of 
fMRI studies in youth with conduct problems. Neuroscience and Biobehavioral Reviews, 91, 69-90. https://doi.org/10.1016/j. neubiorev.2016.10.022.

Bradley, M. M., Codispoti, M., Cuthbert, B. N., \& Lang, P. J. (2001). Emotion and motivation I: Defensive and appetitive reactions in picture processing. Emotion, 1, 276-298. https://doi.org/10.1037// 1528-3542.1.3.276

Colins, O. F., Andershed, H., Salekin, R. T., \& Fanti, K. A. (2018). Comparing different approaches for subtyping children with conduct problems: Callous-unemotional traits only versus the multidimensional psychopathy construct. Journal of Psychopathology and Behavioral Assessment, 40, 6-15. https://doi.org/10.1007/s10862018-9653-y.

Cook, E.W., \& Turpin, G. (1997). Differentiating orienting, startle, and defense responses: The role of affect and its implications for psychopathology. In P. J. Lang, R. F. Simons, \& M. T. Balaban (Eds.). Attention and orienting: sensory and motivational processes ( $\mathrm{pp}$. 137-164). Erlbaum.

Cuff, B. M. P., Brown, S. J., Taylor, L., \& Howat, D. J. (2016). Empathy: A review of the concept. Emotion Review, 8, 144-153. doi: https:// doi.org/10.1177/1754073914558466 er.sagepub.com

Dadds, M. R., El Masry, Y., Wimalaweera, S., \& Guastella, A. J. (2008). Reduced eye gaze explains "fear blindness" in childhood psychopathic traits. Journal of the American Academy of Child and Adolescent Psychiatry, 47, 455-463. https://doi.org/10.1097/CHI. 0b013e31816407f1.

Dadds, M. R., Jambrak, J., Pasalich, D., Hawes, D. J., \& Brennan, J. (2011). Impaired attention to the eyes of attachment figures and the developmental origins of psychopathy. The Journal of Child Psychology and Psychiatry, 52, 238-245. https://doi.org/10.1111/j. 1469-7610.2010.02323.x.

Dadds, M. R., Whiting, C., \& Hawes, D. J. (2006a). Associations among cruelty to animals, family conflict, and psychopathic traits in childhood. Journal of Interpersonal Violence, 21, 411-429. https://doi. org/10.1177/0886260505283341.

Dadds, M. R., Perry, Y., Hawes, D. J., Merz, S., Riddel, A. C., Haines, D. J., Solak, E., \& Abeygunawardane, A. I. (2006b). Attention to the eyes and fear-recognition deficits in child psychopathy. The Britisch Journal of Psychiatry, 189, 280-281. https://doi.org/10.1192/bjp. bp.105.018150.

de Wied, M., van der Baan, H., Raaijmaakers, Q., de Ruiter, C., \& Meeus, W. (2014). Factor structure and construct validity of the Dutch version of the antisocial process screening device. Journal of Psychopathology and Behavioral Assessment, 36, 84-92. https:// doi.org/10.1007/s10862-013-9371-4.

de Wied, M., Gispen-de Wied, C., \& van Boxtel, A. (2010). Empathy dysfunction in children and adolescents with disruptive behavior disorders. European Journal of Pharmacology, 626, 97-103. https://doi.org/10.1016/j.ejphar.2009.10.016.

de Wied, M., Goudena, P. P., \& Matthys, W. (2005). Empathy in boys with disruptive behavior disorders. Journal of Child Psychology and Psychiatry, 46, 867-880. https://doi.org/10.1111/j.1469-7610.2004. 00389.x.

de Wied, M., van Boxtel, A., Matthys, W., \& Meeus, W. (2012). Verbal, facial and autonomic responses to empathy-eliciting film clips by disruptive male adolescents with high versus low callousunemotional traits. Journal of Abnormal Child Psychology, 40, 211-223. https://doi.org/10.1007/s10802-011-9557-8.

de Wied, M., van Boxtel, A., Posthumus, J. A., Goudena, P. P., \& Matthys, W. (2009). Facial EMG and heart rate responses to emotion-inducing film clips in boys with disruptive behavior disorders. Psychophysiology, 46, 996-1004. https://doi.org/10.1111/j. 1469-8986.2009.00851.x.

Eisenberg, N., Fabes, R. A., Bustamante, D., Mathy, R. M., Miller, P. A., \& Lindholm, E. (1988a). Differentiation of vicariously induced emotional reactions in children. Developmental Psychology, 24, 237-246. https://doi.org/10.1037/0012-1649.24.2.237.

Eisenberg, N., Schaller, M., Fabes, R. A., Bustamante, D., Mathy, R. M., Shell, R., \& Rhodes, K. (1988b). Differentiation of personal distress and sympathy in children and adults. Developmental Psychology, 24, 766-775. https://doi.org/10.1037/0012-1649.24.6.766.

Endenburg, N. (1995). The attachment of people to companion animals. Anthrozoös, 8, 83-89. https://doi.org/10.2752/ 089279395787156446.

Fanti, K. A., Eisenbarth, H., Goble, P., Demetriou, C., Kyranides, M. N., Goodwin, D., et al. (2019). Psychophysiological activity and reactivity in children and adolescents with conduct problems: A systematic review and meta-analysis. Neuroscience and Biobehavioral Reviews, 100, 98-107. https://doi.org/10.1016/j.neubiorev.2019. 02.016 .

Ferdinand, R. F., \& van der Ende, J. (2002). NIMH-DISC-IV: Diagnostic interview schedule for children (authorized Dutch version). Rotterdam: Erasmus MC/Sophia Kinderziekenhuis Rotterdam.

Frick, P. J., \& Hare, R. D. (2001). Antisocial process screening device (APSD). Toronto: Multi-Health Systems.

Frick, P. J., Ray, J. V., Thornton, L. C., \& Kahn, R. E. (2014). Can callous-unemotional traits enhance the understanding, diagnosis, and treatment of serious conduct problems in children and adolescents? A comprehensive review. Psychological Bulletin, 140, 1-57. https://doi.org/10.1037/a0033076.

Gillen, C. T. A., Lee, Z., Salekin, K. L., Iselin, A. M. R., Harrison, N. A., Clark, A. P., Colins, O. F., \& Salekin, R. T. (2018). Psychopathic traits in adolescence: The importance of examining components in face processing, voice processing, and emotional skill. Journal of Psychopathology and Behavioral Assessment, 40, 50-59. https:// doi.org/10.1007/s10862-018-9656-8.

Gomez, P., Zimmermann, P., Guttormsen-Schär, S., \& Danuser, B. (2005). Respiratory responses associated with affective processing of film stimuli. Biological Psychology, 68, 223-235. https://doi.org/ 10.1016/j.biopsycho.2004.06.003.

Grommon, E., Carson, D. C., \& Kenny, L. (2020). An experimental trial of a dog-training program in a juvenile detention center. Journal of Experimental Criminology, 16, 299-309. https://doi.org/10.1007/ s11292-018-9346-2.

Gullone, E. (2014). An evaluative review of theories related to animal cruelty. Journal of Animal Ethics, 4, 37-57. https://doi.org/10.5406/ janimalethics.4.1.0037.

Hare, R. D. (1991/2003). Manual for the revised psychopathy checklist (1st and 2nd edn). Toronto, ON, Canada: Multi-Health Systems.

Hartman, C., Hageman, T., Williams, H. W., St. Mary, J., \& Ascione, F. R. (2019). Exploring empathy and callous-unemotional traits as predictors of animal abuse perpetrated by children exposed to intimate partner violence. Journal of Interpersonal Violence, 34, 2419-2437. https://doi.org/10.1177/0886260516660971.

Hastrup, J. L. (1986). Duration of initial heart rate assessment in psychophysiology: Current practices and implications. Psychophysiology, 23, 15-18. https://doi.org/10.1111/j.1469-8986.1986.tb00584.x.

Hawkins, R. D., Hawkins, E. L., \& Williams, J. M. (2017). Psychological risk factors for childhood nonhuman animal cruelty: A systematic review. Society \& Animals: Journal of Human-Animal Studies, 25, 280-312. https://doi.org/10.1163/15685306-12341448.

Hoffman, M. L. (2000). Empathy and moral development. New York: Cambridge University Press.

Keysers, C., \& Gazzola, V. (2014). Dissociating the ability and propensity for empathy. Trends in Cognitive Sciences, 18, 163-166. https:// doi.org/10.1016/j.tics.2013.12.011.

Kreibig, S. D., Wilhelm, F. H., Roth, W. T., \& Gross, J. J. (2007). Cardiovascular, electrodermal, and respiratory response patterns to fear- and sadness-inducing films. Psychophysiology, 44, 787-806. https://doi.org/10.1111/j.1469-8986.2007.00550.x. 
Lilienfeld, S. O. (2018). The multidimensional nature of psychopathy: Five recommendations for research. Journal of Psychopathology and Behavioral Assessment, 40, 79-85. https://doi.org/10.1007/ s10862-018-9657-7.

Longobardi, C., \& Badenes-Ribera, L. (2019). The relationship between animal cruelty in children and adolescent and interpersonal violence: A systematic review. Aggression and Violent Behavior, 46, 201211. https://doi.org/10.1016/j.avb.2018.09.001.

Lucia, S., \& Killias, M. (2011). Is animal cruelty a marker of interpersonal violence and delinquency? Results of a Swiss national self-report study. Psychology of Violence, 1, 93-105. https://doi.org/10.1037/ a0022986.

Main, A., Walle, E. A., Kho, C., \& Halpern, J. (2017). The interpersonal functions of empathy: A relational perspective. Emotion Review, 9, 358-366. https://doi.org/10.1177/1754073916669440.

McPhedran, S. (2009). A review of the evidence for associations between empathy, violence, and animal cruelty. Aggression and Violent Behavior, 14, 1-4. https://doi.org/10.1016/j.avb.2008.07.005.

Meffert, H., Gazzola, V., den Boer, J. A., Bartels, A. A. J., \& Keysers, C. (2013). Reduced spontaneous but relatively normal deliberate vicarious representations in psychopathy. Brain, 136, 2550-2562. https:// doi.org/10.1093/brain/awt190.

Merz-Perez, L., Heide, K. M., \& Silverman, I. J. (2001). Childhood cruelty to animals and subsequent violence against humans. International Journal of Offender Therapy and Comparative Criminology, 45, 556-573. 10.1177\%2F0306624X01455003.

Moul, C., Killcross, S., \& Dadds, M. R. (2012). A model of differential amygdala activation in psychopathy. Psychological Review, 119, 789-806. https://doi.org/10.1037/a0029342.

Moul, C., Hawes, D. J., \& Dadds, M. R. (2018). Mapping the developmental pathways of child conduct problems through the neurobiology of empathy. Neuroscience and Biobehavioral Reviews, 91, 34 50. https://doi.org/10.1016/j.neubiorev.2017.03.016.

Parkes, D., \& Signal, T. (2017). Revisiting a link: Animal abuse, bullying, and empathy in Australian youth. Human-Animal Interaction Bulletin, 5, 26-40.

Pijper, J., de Wied, M., van Goozen, S., \& Meeus, W. H. J. (2017). Empathy problems in youth with disruptive behavior disorders, with and without callous unemotional traits. In L. C. Centifanti, \& D. M. Williams (Eds.). The Wiley Handbook of Developmental Psychopathology (pp. 161-178). John Wiley \& Sons Ltd.

Pijper, J., de Wied, M., van Rijn, S., van Goozen, S., Swaab, H., \& Meeus, W. (2018). Executive attention and empathy-related responses in boys with oppositional defiant disorder or conduct disorder, with and without comorbid anxiety disorder. Child Psychiatry and Human Development, 49, 956-965. https://doi.org/10.1007/ s10578-018-0810-z.

Plant, M., van Schaik, P., Gullone, E., \& Flynn, C. (2019). "It's a dog's life": Culture, empathy, gender, and domestic violence predict animal abuse in adolescents- implications for societal health. Journal of Interpersonal Violence, 34, 2110-2137. https://doi.org/ $10.1177 / 0886260516659655$.

Poore, H. E., Watts, A. L., Lilienfeld, S. O., \& Waldman, I. D. (2020). Construct validity of youth psychopathic traits as assessed by the antisocial process screening device. Psychological Assessment, 32, 527-540. https://doi.org/10.1037/pas0000809.

Prguda, E., \& Neumann, D. L. (2014). Inter-human and animal-directed empathy: A test for evolutionary biases in empathetic responding. Behavioural Processes, 108, 80-86. https://doi.org/10.1016/j. beproc.2014.09.012.

Ribeiro da Silva, D., Rijo, D., \& Salekin, R. T. (2020). Psychopathic traits in children and youth: The state-of-the-art after 30 years of research. Aggression and Violent Behavior, 55, 101454. https://doi.org/10. 1016/j.avb.2020.101454.

Salekin, R. T. (2017). Research review: What do we know about psychopathic traits in children? Journal of Child Psychology and Psychiatry, 58, 1180-1200. https://doi.org/10.1111/jcpp.12738.

Salekin, R. T., Andershed, H., Batky, B. D., \& Bontemps, A. P. (2018). Are callous unemotional (CU) traits enough? Journal of Psychopathology and Behavioral Assessment, 40, 1-5. https://doi. org/10.1007/s10862-018-9663-9.

Singer, T., \& Klimecki, O. M. (2014). Empathy and compassion. Current Biology, 24, 875-878. https://doi.org/10.1016/j.cub.2014.06.054.

Urbonaviciute, G., \& Hepper, E. G. (2020). When is narcissism associated with low empathy? A meta-analytic review. Journal of Research in Personality. Advanced online publication. https://doi. org/10.1016/j.jrp.2020.104036, 89, 104036.

van Baardewijk, Y., Stegge, H., Bushman, B. J., \& Vermeiren, R. (2009). Psychopathic traits, victim distress and aggression in children. Journal of Child Psychology and Psychiatry, 50, 718-725. https:// doi.org/10.1111/j.1469-7610.2008.02023.x.

Viding, E., \& McCrory, E. (2019). Towards understanding atypical social affiliation in psychopathy. The Lancet Psychiatry, 6, 437-444. https://doi.org/10.1016/S2215-0366(19)30049-5.

Wechsler, D. (1974). Manual for the Wechsler intelligence scale for children-revised. New York: Psychological Corporation.

Westbury, H. R., \& Neumann, D. L. (2008). Empathy-related responses to moving film stimuli depicting human and non-human animal targets in negative circumstances. Biological Psychology, 78, 6674. https://doi.org/10.1016/j.biopsycho.2007.12.009.

Zhou, Q., Valiente., C., \& Eisenberg, N. (2003). Empathy and its measurement. In S.J. Lopez, \& C.R. Snyder (Eds.), Positive psychological assessment: A Handbook of Models and Measures (pp. 269284). Washington, DC: American Psychological Association.

Publisher's Note Springer Nature remains neutral with regard to jurisdictional claims in published maps and institutional affiliations. 